\title{
Effect of Gas Sparging on Fouling and Fouling Mechanism During Microfiltration of Pineapple Juice and Coconut Water
}

\author{
A. Laorko ${ }^{1,2}$, W. Youravong, ${ }^{2,1^{4}}$, \& S. Tongchitpakdee ${ }^{3}$ \\ ${ }^{1}$ Department of Food Technology, Faculty of Agro-Industry Prince of Songkla University, Hat Yai, 90112, Thailand \\ ${ }^{2}$ Membrane Science and Technology Research Center \\ Prince of Songlela University, Hat Yai, 90112, Thailand \\ ${ }^{3}$ Department of Food science and Technology, Faculty of Agro-Industry, Kasetsart University, Bangkok, 10900, 'Thailand
}

\begin{abstract}
Flux reduction due to fouling is the major problem during microfiltration. This study aimed to investigate the role of gas sparging, an effective technique for flux enhancement, on fouling and fouling mechanism during microfiltration pineapple juice and coconut water. A hollow fiber membrane was used and the experiments were performed at cross flow velocity (CFV) of $1.5 \mathrm{~m} / \mathrm{s}$, transmembrane pressure (TMP) of 0.7 bar for pineapple juice and CFV of $1.6 \mathrm{~m} / \mathrm{s}$, TMP of 0.6 bar for coconut water, as varyirig gas injection factors (e). It was found that the fouling mechanism during microfiltration of pineapple juice and coconut water began with complete blocking; followed by an intermediate blocking and finally cake filtration. The use of gas sparging did not affect the sequence of fouling mechanism but affected both intensity duration of these fouling mechanisms. The duration of complete blocking stage was about 5-6 min at the beginning of the microfiltration for both feed. The initial points of defined cake filtration stages reduced from 1.3 to $0.9 \mathrm{~h}$ for pineapple juice and 1.0 to $0.67 \mathrm{~h}$ for coconut water when the e was varied from 0 to 0.35 . Regarding fouling resistance analysis, increase in gas injection factor could significantly reduce the reversible fouling, external irreversible fouling but internal irreversible fouling.
\end{abstract}

' Keywords: Coconut water, fouling, gas sparging, microfiltration, pineapple juice

\subsection{INTRODUCTION}

One of the major limitations of microfiltration in various applications is membrane fouling. The membrane fouling typically manifests it as decay in permeate flux and alteration in membrane selectivity. These changes continue throughout the membrane process and eventually require extensive cleaning or replacement of the membrane [1]. Thus, the fouling in cross-flow microfiltration is a key factor affecting the economic and commercial viability of a membrane system which essentially depended on the permeate fluxes obtained and their stability with filtration time. To prevent or reduce membrane fouling, several research studies have focused on hydrodynamic improvement method. The effective methods have been recently developed to reduce fouling and/or to enhance permeate flux during microfiltration process such as critical flux operation [2,3], backplusing [4] and gas sparging [3]. The gas sparging is one of the techniques that not only successfully enhance the permeate flux during microfiltration and ultrafiltration but also pose less risk.

\footnotetext{
*Corresponding to: W. Youravong (email: wirote.y@psu.ac.th)
} 
to the membrane. In addition, the created-gas bubbles are easily to be separated from the process stream [5]. In order to enhance its economy and efficiency, understanding the membrane fouling mechanism is necessary for the further development.

There are several factors, affecting the fouling and fouling mechanism during microfiltration process such as the cross-flow velocity (CFV), transmembrane pressure (TMP), membrane properties, feed properties etc. The effect of CFV and TMP on the fouling mechanisms during ultrafiltration of polyethylene glycol (PEG) was studied [6]. The result showed that the best fitted model of experimental data corresponded to the cake layer formation model followed by the intermediate blocking model. Moreover, they found that the fouling mechanism depended on the operating conditions. For example, cake layer formation was only observed at the highest TMP and the lowest CFV. For fouling mechanism of pineapple juice, complete pore blocking predominated in the ceramic membrane while cake formation predominated in hollow fiber membranes [7]. The fouling mechanism of kiwifruit juice dominated by cake formation [8]. Fouling mechanism of low-concentration-non leaving yeast suspension was intermediate blocking at the beginning of the filtration followed by cake formation [9]. The feed concentration plays an important role in fouling mechanism during microfiltration of polysaccharide [10]. The cake filtration model appear to fit at a low concentration of polysaccharide solution $(20 \mathrm{mg} / \mathrm{l})$ while with higher concentration, identification of the predominant fouling mechanism was difficult. As mention above, the difference of feed solution and

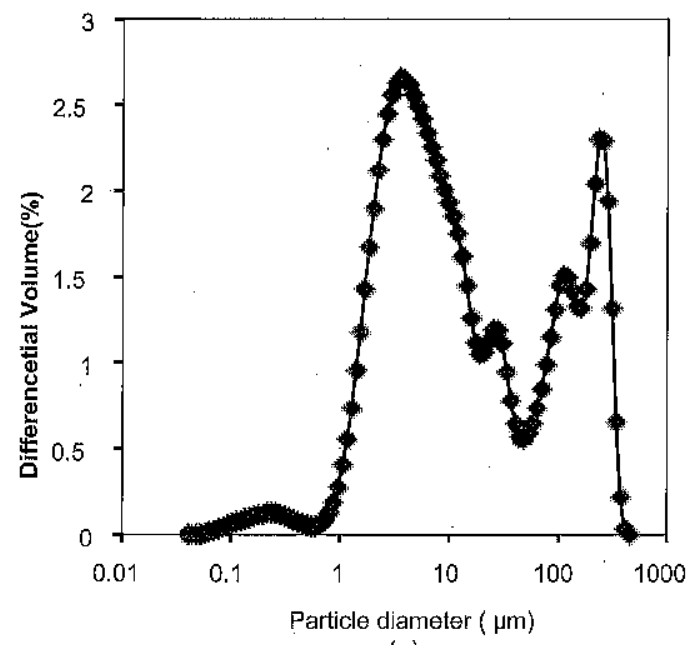

(a) operating parameters present the different fouling and fouling mechanism. Therefore, in order to control the fouling, it is importance to understand its key characters and behavior of fouling during microfiltration process.

This study aimed to understand the role of gas sparging on fouling and fouling mechanism during microfiltration of pineapple juice (rich in suspended solid) and coconut water (less suspended solid). The effect of gas injection factor (e) on fouling mechanism and membrane resistance were also investigated.

\subsection{EXPERIMENTAL}

\subsection{Preparation of Fruit Juice}

Fresh pineapples (Ananus Comosus L. Merr.) were cleaned by tap water. After the shells were peeled by a stainless steel knife, the fresh pineapples were chopped into pieces of $1 \mathrm{~cm}^{3}$ and the juice was extracted by a hydraulic press. The total soluble solid and $\mathrm{pH}$ values of the juice were in the range of $12.2-14.2^{\circ}$ Brix and 3.5-4.0 respectively. The fresh pineapple juice was stored at $4^{\circ} \mathrm{C}$ before use. Before processing with membrane filtration, the pineapple juice was treated with $0.03 \%(\mathrm{~V} / \mathrm{V})$ of commercial pectinese (Pectinex ${ }^{(1)}$ ultra SP-L $),(P A(E N))$ at room temperature $\left(25 \pm 3^{\circ} \mathrm{C}\right)$ for $60 \mathrm{~min}$ [11].

Young coconut of 4-5 month old from local farm in Songkhla province, Thailand was used throughout this study. The coconut water obtained from the open nut fruit was collected in a clean container. After that it was filtrated though a cloth sheet to remove large

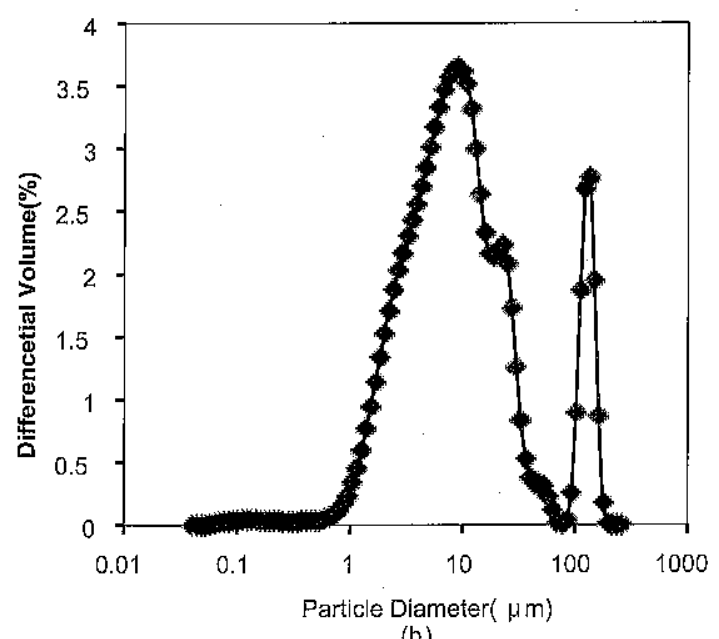

(b)

Figure 1 Particle size distribution of pre-treated enzymatic pineapple juice (a) and coconut water (b) 
solid particles which may block the inlet lumen of the hollow fiber membrane. The total soluble solid in the coconut water obtained was in the range of $5-7^{\circ}$ Brix.

Particle size distribution in pineapple juice and coconut water was detected by a Laser Particle Size Analyzer (LS230, Beckman Coulter, USA). The mean particle size was about 58.92 um for pineapple juice and $25 \mu \mathrm{m}$ for coconut water (Figure 1). It is important to note that the concentration of suspended particle in pineapple juice was much higher than that of coconut water.

\subsection{Microflitration System}

The membrane system used was a polysulfone hollow fiber module (Amersham Biosciences, UK) with a fiber diameter and length of $1 \mathrm{~mm}$. and $30 \mathrm{~cm}$. respectively. The membrane pore size was $0.2 \mu \mathrm{m}$ for pineapple juice and $0.1 \mu \mathrm{m}$ for coconut water. The effective membrane area was $0.011 \mathrm{~m}^{2}$. The membrane system consisted of a 8 liter stainless steel jacket-feed tank, variable-feed pump (Leeson, USA) and transducers (MBS 3000, Danfoss, Denmark) for pressure measurement of the feed, retentate and permeate. The temperature of the feed was controlled by circulating cooling water through a jacket-feed tank. The CFV and TMP were controlled using needle permeate valve and variable speed-feed pump. The balance (GF-3000, A\&D, Japan), connecting the computer was used to measure the permeate flux.

The compressed nitrogen gas was injected into the inlet of feed pipe through a $Y$ tube tubular piece. The gas flow rate was controlled and measured by a gas flow meter (RMB-50D-SSV, Dwyer, USA) combined with pressure gauge (2419-2C-P, CKD, Japan), The gasliquid dual flow pattern depends on the gas injection factor $(\varepsilon)$ which equals to $U_{g} /\left(U_{g}+U\right), U_{g}$ and $U_{l}$ are the superficial gas and liquid flow rate or flow velocity, respectively. The dual flow pattern changes from bubble flow $(0<\varepsilon<0.2)$ over slug flow $(0.2<\varepsilon<0.9)$ to annular flow $(0.9<\varepsilon<1.0)$ [5]. In this study, the $\varepsilon$ applied were $0,0.15,0.25$ and 0.35 , varying from bubble flow to slug flow. The experiments were performed at the CFV of $1.5 \mathrm{~m} / \mathrm{s}$ and the TMP of 0.7 bar for pineapple juice and CFV of $1.6 \mathrm{~m} / \mathrm{s}$, TMP of 0.6 bar for coconut water. All experiments were carried out at a temperature of $20^{\circ} \mathrm{C}$. Both permeate and retentate were recycled back to the feed tank. Therefore, the concentration in the feed remained constant.

\subsection{Models of Membrane Fouling}

Generally, permeate flux of microfiltration process can be described by Darcy's Law as follow:

$$
J=\frac{T M P}{\mu R_{t}}
$$

where $J$ is the volumetric flux of permeate across the membrane $(\mathrm{m} / \mathrm{s}), T M P$ is the transmembrane pressure $(\mathrm{Pa}), \mu$ is the permeate viscosity $(\mathrm{Pa} . \mathrm{s})$ and $R_{\mathrm{t}}$ is the total hydraulic resistance $(1 / \mathrm{m})$.

Four constant pressure blocking filtration laws including standard blocking (each particle arriving to the membrane deposits onto the internal pore walls leading to a decrease of pore volume), intermediate blocking (each particle can settle on other particle previously arrived and already blocking some pores or it can aiso directly biock some membrane area), complete blocking (each particle reaching the membrane blocks a pore) and cake filtration (particles deposit onto the membrane surface and a filter cake forms are directly applicable for description of flux decline during deadend membrane filtration [12]. By modification of the relevant mass balance, the equivalent equations as follows have also been obtained for description of flux decline during cross flow membrane filtration $[13,14]$.

Standard blocking model:

$J^{-1 / 2}=J_{0}^{-1 / 2}+k_{s} t$

Intermediate blocking model:

$J^{1}=J_{0}^{-i}+k_{i} t$

Complete blocking model: :

$\ln \left(J^{-1}\right)=\ln \left(J_{0}^{-1}\right)=k_{b} t$

Cake filtration model:

$J^{2}=J_{0}^{-2}+k_{c} t$

In these models, $k_{\mathrm{s}}, k_{\mathrm{i}}, k_{\mathrm{b}}, k_{\mathrm{c}}$ are constant relating to each model respectively, $t$ is the filtration time and $J_{0}$ is the initial permeate flux. The fouling mechanism can be analyzed by fitting experimentai data to Equations (2), (3), (4) and (5). The linear stages in the figures based on these equations indicate the type and duration of the fouling. 


\subsection{Membrane Fouling and Resistances Analysis}

The resistance to the permeate flow during microfiltration was defined by Darcy's law (Equation 1). The total resistance is divided as follows,

$$
\begin{aligned}
& R_{t}=R_{n t}+R_{t f}+R_{i f} \\
& R_{i f f}=R_{i f-i n}+R_{i f-z x t}
\end{aligned}
$$

where $R_{t}$ is the sum of $R_{m}$ (membrane resistance), $R_{r f}$ (the resistance caused by reversible fouling) and $R_{i f}$ (the resistance caused by irreversible fouling). Furthermore, $R_{i f}$ is divided into two types, $R_{i f-i n}$ (the resistance caused by internal irreversible fouling) and $R_{i f-e x}$ (the resistance caused by external irreversible fouling). In this study, $R_{r f}$ was defined as the fouling which could be removed by water flushing. The residual fouling after water flushing was $R_{i f}$ and it was further cleaned by chemical cleaning. The resistance defined by equation (6) and (7) could be evaluated by measurement of water flux during cleaning process. $R_{m}$ was determined by measurement of water flux of clean membrane. After filtration of the juices, the water was flushed through the membrane surface to removed $R_{r f}$ while permeate valve was closed. Water flushing was operated using clean water at CFV of 1.4 $\mathrm{m} / \mathrm{s}$ and TMP of 0.3 bar for $15 \mathrm{~min}$. After the first water flushing, the permeate valve was opened and water flux was measured to determined residual fouling resistance (i.e., $R_{m}+R_{i f}$ ). Then permeate valve was closed again. A chemical cleaning was applied by circulating $0.5 \mathrm{~N}$



$\mathrm{NaOH}$ solution at $50^{\circ} \mathrm{C}, \mathrm{TMP} 0.3$ bar and CFV of $1.4 \mathrm{~m} / \mathrm{s}$ for $40 \mathrm{~min}$ to remove external irreversible fouling. After that the chemical cleaning solution was removed by water flushing. Then the water flux was measured to evaluated residual resistance (i.e. $R_{m}+R_{i f-i s}$ ). After that the $R_{i f-i n}$ was removed by circulating $50 \mathrm{ppm}$. of $\mathrm{NaOCl}$ at $50^{\circ} \mathrm{C}, \mathrm{TMP}$ of $0.3 \mathrm{bar}$ and $\mathrm{CFV}$ of $1.4 \mathrm{~m} / \mathrm{s}$ for at least $40 \mathrm{~min}$. With $R_{t}$ obtained after filtration of juice, use of equation. (1) and the results from cleaning procedure combining with equation (6) and (7) all types of resistances could be worked out.

\subsection{RESULTS AND DICUSSION}

\subsection{Effect of Gas Sparging on Flux Behavior}

Figure 2 shows the permente flux profile during microfiltration of pineapple juice (a) and coconut water (b) with various $\varepsilon$. The result showed that the gas sparging could significantly enhance permeate flux during running time of 2 hours under total recycle mode. It was observed that a steady flux was improved as e increase. The whole microfiltration process could be divided into two stages, i.e. flux decline stage and steady flux stage. Varying e from 0.15 to 0.35 could improve steady flux from 23.7 to $58.2 \%$ for pineapple juice while the improvement of coconut water flux varied from 11.5 to $42.1 \%$. Thus the higher of e resulted in the higher of permeate flux. The permeate flux improvement (\%) of



Figure 2 Effect of gas sparging on permeate flux during the microfiltration of pineapple juice at $\mathrm{CFV}=1.5 \mathrm{~m} / \mathrm{s}$, $\mathrm{TMP}=0.7$ bar (a) and coconut water $\mathrm{CFV}=1.6 \mathrm{~m} / \mathrm{s}, \mathrm{TMP}=0.6 \mathrm{bar}(\mathrm{b})$ with various $\varepsilon(\diamond, \varepsilon=0 ; \square, \varepsilon=$ $0.15 ; \triangle, \varepsilon=0.25 ; \times, \varepsilon=0.35$ ) 
pineapple was higher than that of coconut water. Since the pineapple juice contained larger particle size and higher concentration of suspended solid than coconut water, thus more severe concentration polarization was expected. It have been suggested that the mechanism of Alux enhancement is related to the distuption of the concentration polarization layer and improved mass transfer [5].

\subsection{Effect of Gas Sparging on Fouling Mechanism}

In practice, all fouling phenomena, e.g. adsorption, pore blocking and cake layer formation might occur simultaneously because of the complexity of the feed composition, operating conditions and membrane properties. However it is possible to detect one or more dominant fouling mechanisms at different state of membrane filtration process. In this study the experimental data was tested with fouling models, expressed by equation (2) to (5). The selected lincar: phase of the curves, indicated the intensity and duration of fouling was also analyzed.

The fitting of experimental data to these models permit to distinguish if the permeate flux decline is controlled by cake layer formation or pore blocking. When pore blocking occurs, it can take place inside the pores (standard blocking) or outside them

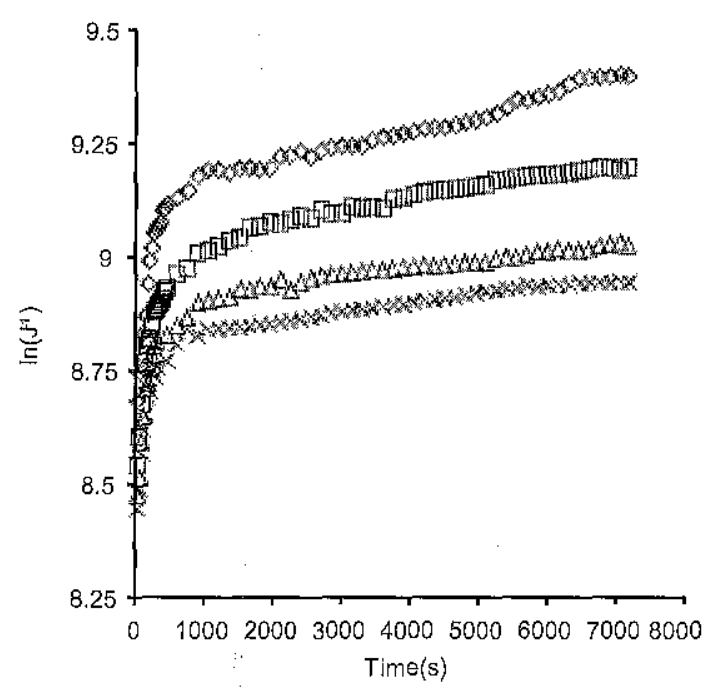

(intermediate and complete blocking). It has been proved that the fouling should start with a complete blocking followed by an intermediate blocking and a cake filtration process if the molecule is much greater than the pore [15]. Most particie size of pineapple juice and coconut water ranged from 0.9 to $100 \mu \mathrm{m}$ and 0.9 to $80 \mu \mathrm{m}$ respectively (the smaller and larger particles were negligible). Comparing to the mean membrane pore size used $(0.1$ and $0.2 \mu \mathrm{m})$, the sizes of suspended particles and their possible aggregates were much larger than the membrane pore size. Figure 3 and 4 show the fitting of the experimental results to the complete blocking model of pineapple juice and coconut water according equation (4). It could be seen that only the data at the initial short period could be fitted to the complete blocking model. The linear phase was defined with coefficient of linear regression $\left(R^{2}\right)$, shown in Table 1. The duration of complete blocking stage of pineapple juice and coconut water was about 5-6 min from the beginning of the microfiltration (Table 2). The $k_{b}$ (equation 4 ) of both feeds slightly decreased as the gas injection factor increase. The reason was probably duc to the higher $\mathrm{\varepsilon}$ present more bubble near the membrane surface, reducing the attachment of particle on the membrane pore. According to the mechanism of complete blocking, a clean membrane surface is required to allow the blocking of the membrane pore by

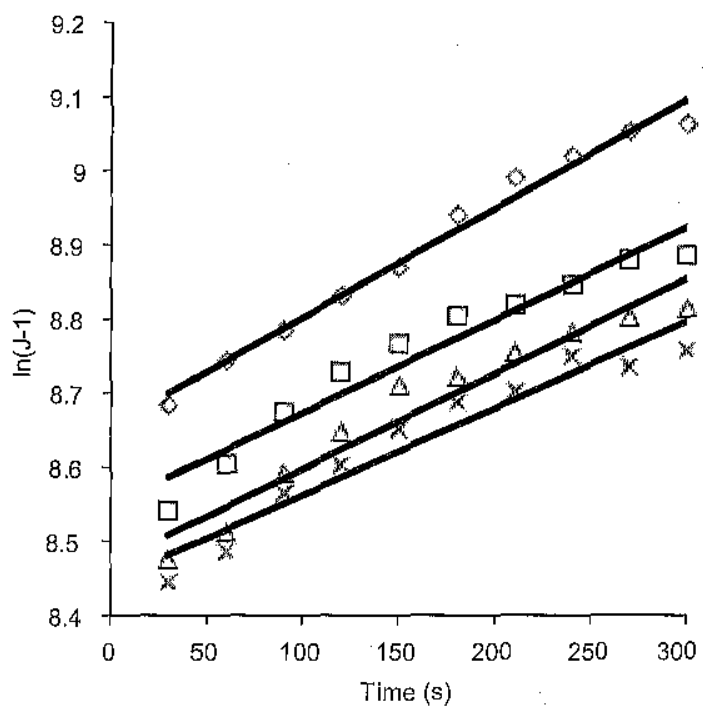

Figure 3 Effect of gas sparging on the fouling due to complete blocking during the microfiltration of pineapple juice with various $\varepsilon$ at $\mathrm{CFV}=1.5 \mathrm{~m} / \mathrm{s}$ and $\mathrm{TMP}=0.7 \mathrm{bar}(\diamond, \varepsilon=0 ; \square, \varepsilon=0.15 ; \triangle$, $\varepsilon=0.25 ; x, \varepsilon=0.35)$ a, complete blocking model fitted to the flux data; $b$, selected linear phase of complete blocking model 



Figure 4 Effect of gas sparging on the fouling due to complete blocking during the microfiltration of coconut water with various $\varepsilon$ at $C F V=1.6 \mathrm{~m} / \mathrm{s}$ and $\operatorname{TMP}=0.6 \operatorname{bar}(\diamond, \varepsilon=0 ; \square, \varepsilon=0.15 ; \Delta$, $\varepsilon=0.25 ; x, \varepsilon=0.35$ ) a, complete blocking model fitted to the flux data; b, selected linear phase of complete blocking mode

Table 1 Kinetic constant of fouling mechanism model during microfiltration of pineapple juice and coconut water with various gas injection factors (e)

\begin{tabular}{|l|l|l|l|l|l|l|}
\hline \multirow{2}{*}{$\varepsilon$} & \multicolumn{3}{|c|}{ Pineapple juice } & \multicolumn{3}{c|}{ Coconut water } \\
\cline { 2 - 7 } & $k_{\mathrm{b}} \times 10^{-2}$ & \multicolumn{1}{c|}{$k_{\mathrm{i}}$} & $k_{\mathrm{c}}$ & $k_{\mathrm{b}} \times 10^{-2}$ & $k_{\mathrm{i}}$ & $k_{\mathrm{c}}$ \\
\hline$\varepsilon=0$ & $0.15\left(0.98^{*}\right)$ & $0.36(0.95)$ & $12694(0.97)$ & $0.20(0.99)$ & $0.56(0.98)$ & $763(0.97)$ \\
\hline$\varepsilon=0.15$ & $0.13(0.94)$ & $0.39(0.91)$ & $3599(0.96)$ & $0.19(0.96)$ & $0.56(0.98)$ & $610(0.97)$ \\
\hline$\varepsilon=0.25$ & $0.13(0.94)$ & $0.27(0.88)$ & $2346(0.96)$ & $0.18(0.96)$ & $0.53(0.98)$ & $527(0.99)$ \\
\hline$\varepsilon=0.35$ & $0.12(0.93)$ & $0.20(0.87)$ & $1788(0.95)$ & $0.16(0.97)$ & $0.46(0.99)$ & $523(0.98)$ \\
\hline
\end{tabular}

* $\mathrm{R}^{2}$

Table 2 Duration time of fouling mechanism during microfiltration of pineapple juice with various gas injection factors

\begin{tabular}{llccc}
\hline Juice & $\varepsilon$ & \multicolumn{3}{c}{ Duration time (s) } \\
\cline { 3 - 5 } Pineapple juice & & Complete blocking & Intermediate blocking & Cake filtration \\
& $\varepsilon=0.0$ & $0-300$ & $300-4650$ & $4650-7230$ \\
& $\varepsilon=0.15$ & $0-300$ & $300-4200$ & $4200-7230$ \\
\hline \multirow{3}{*}{ Coconut water } & $\varepsilon=0.25$ & $0-300$ & $300-3900$ & $3900-7230$ \\
& $\varepsilon=0.35$ & $0-300$ & $300-3300$ & $3300-7230$ \\
& $\varepsilon=0.0$ & $0-390$ & $390-3630$ & $3630-7230$ \\
\hline & $\varepsilon=0.15$ & $0-390$ & $390-3030$ & $3030-7230$ \\
& $\varepsilon=0.25$ & $0-360$ & $360-2730$ & $2730-7230$ \\
& $\varepsilon=0.35$ & $0-390$ & $390-2430$ & $2430-7230$ \\
\hline
\end{tabular}


particles arriving membrane surface $[12,13]$. Therefore, the complete blocking only occurred in the initial stage of microfiltration and for a short period of time.

The cake layer fouling mechanism occurs when solute molecules are much greater than the membrane pore. Consequently, they are unable to enter the membrane pores. Some of the main factors that have the main influence on the cake layer resistance are: molecular deformation, cake compression and cake layer thickness [6]. Gencrally, the dominant fouling mechanism would be cake filtration at the end of filtration if a steady permeate flux is achieved. In this study, the steady fluxes were observed. The data of flux were fitted to the cake filtration model from the end of the runs (Figure 5 and 6). All data could fit to cake filtration model with defined coefficient of linear regression at the end of microfiltration processes. It was observed that the stages dominated by cake filtration occurred earlier when gas sparging was applied (Figure $5 \mathrm{~b}$ and $6 \mathrm{~b}$. The initial points of defined cake filtration stages dominated at the filtration time of $1.3,1.2,1.1$ and $0.9 \mathrm{~h}$ (pineapple juice, Figure 5b) and 1.0, 0.84,0.75 and $0.67 \mathrm{~h}$ (coconiut water, Figure 6b) for $\mathrm{e}$ of $0,0.15$, 0.25 and 0.35 respectively. In addition to the duration of stages dominated by cake filtration, gas sparging had influence on $k_{c}$ (equation 5) as well. The $k_{c}$ of pineapple juice were $12694,3599,2346$ and 1788 while the $k_{c}$ of coconut water were $763,610,527$ and 523 when the $\varepsilon$ of $0,0.15,0.25$ and 0.35 were applied respectively. The lower $k_{t}$ indicated a lower intensive cake layer. The

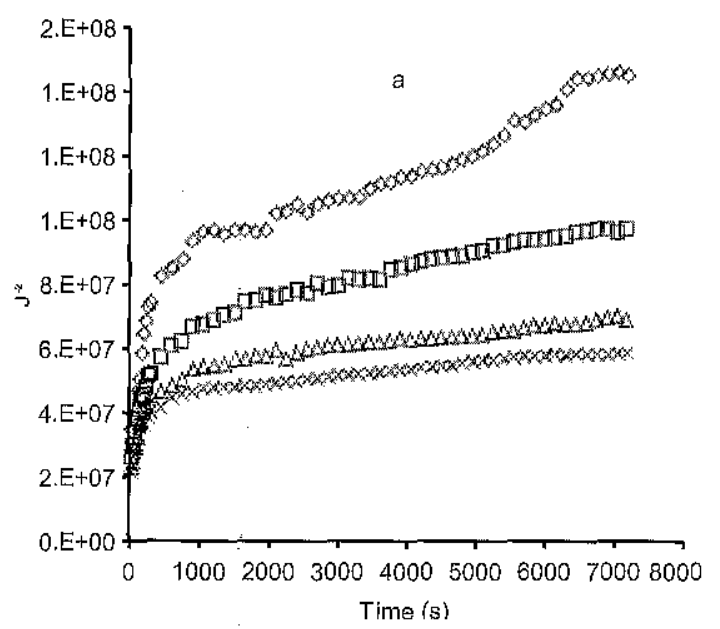

higher of e produced the higher the vertex of the particle near the membrane surface leading to lcss compact of the cake. Therefore, the higher steady flux was observed when $\varepsilon$ was increased. The result suggested that the higher e significantly rcduced the cake formation on the membrane surface [16]. This reason could be explained by both solvent mass transportation and solute mass transportation. Gas induced bubbles in the flow channel could increase turbulence leading to flux enhancement. The reduction of $k_{t}$ was in accordance with the studied of [17]. They found that the $k_{c}$ decreased when the higher CFV during microfiltration of pineapple wine was applied. Comparing to $k$ between the two juices, the $k_{\varepsilon}$ of pineapple juice was much higher than the $k_{t}$ of coconut water. The reason was due to the pineapple juice had more severe particles and foulants than that the coconut water, therefore it was more cake, formed on the membrane surface.

Apart from the complete blocking dominated stage and cake filtration dominated stages, the dominant fouling should be intermediate blocking in the middle of microfiltration process [15]. Figure 7 and 8 show the fitting of the experiment permeate flux of pineapple juice and coconut water to the intermediate blocking model (equation (3)) for all experimental conditions. The intermediate blocking fouling mechanism occurs when the membrane pore size is similar to the size of solute molecules. Membrane pores are blocked on near theirs the entrance in the feed side. However, not all of them are completely blocked. The duration

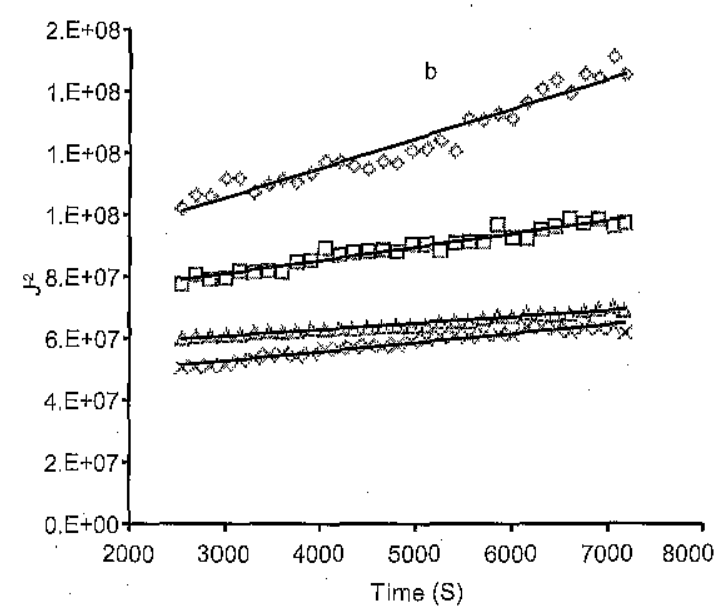

Figure 5 Effect of gas sparging on the fouling due to cake filtration during the microfiltration of pineapple juice with various $\varepsilon$ at $C F V=1.5 \mathrm{~m} / \mathrm{s}$ and $\mathrm{TMP}=0.7 \operatorname{bar}(\diamond, \varepsilon=0 ; \square, \varepsilon=0.15 ; \Delta, \varepsilon=0.25 ; \mathrm{x}$, $\varepsilon=0.35)$ a, cake filtration model fitted to the flux data; $b$, selected linear phase of cake filtration model 



Figure 6 Effcet of gas sparging on the fouling due to cake filtration during the microfiltration of coconut water with various $\varepsilon$ at $\mathrm{CFV}=1.6 \mathrm{~m} / \mathrm{s}$ and $\mathrm{TMP}=0.6$ bar $(0, \varepsilon=0 ; \square, \varepsilon=0.15 ; \square, \varepsilon=0.25$; $x, \varepsilon=0.35)$ a, cake filtration model fitted to the flux data; $b$, selected linear phase of cake filtration model

of intermediate blocking stage of pineapple juice was defined as the period from the end of complete blocking stage evaluated from Figure $3 \mathrm{~b}$ to the beginning of cake filtration dominated stages evaluated from Figure $5 \mathrm{~b}$ while the duration of intermediate blocking stage of coconut water was defined as the period from the end of complete blocking stage evaluated from Figure $4 \mathrm{~b}$ to the beginning of cake filtration dominated stages evaluated from Figure 6b. The use of gas sparging reduced the

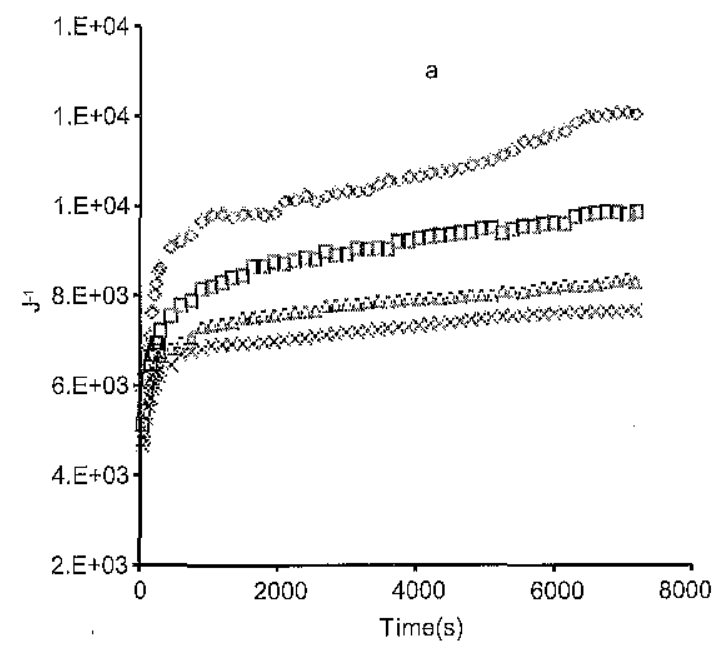

time of intermediate blocking. The shortest duration of intermediate blocking was obtained when the $\varepsilon$ of 0.35 were applied (Figure $7 \mathrm{~b}$ and $8 \mathrm{~b}$ ). As mentioned above, the presence and movement of bubbles in flow could remove larger particles away from the membrane and draw smaller particles to the membrane surface. Hence gas sparging could accelerate the formation of fouling layer on the membrane, consequently reduce the period of intermediate blocking. However, it should be noted that

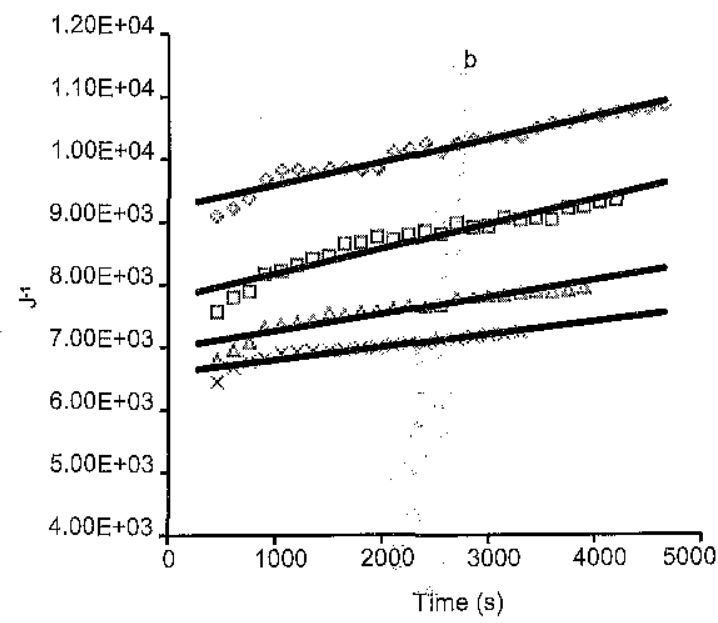

Figure 7 Effect of gas sparging on the fouling due to intermediate blocking during the microfiltration of pineapple juice with various $\varepsilon$ at $C F V=1.5 \mathrm{~m} / \mathrm{s}$ and $T M P=0.7 \operatorname{bar}(\nu, \varepsilon=0 ; \square, \varepsilon=0.15 ; \square$, $\varepsilon=0.25 ; \times, \varepsilon=0.35)$; a, intermediate blocking model fitted to the flux data; $b$, selected linear phase of intermediate blocking model). 

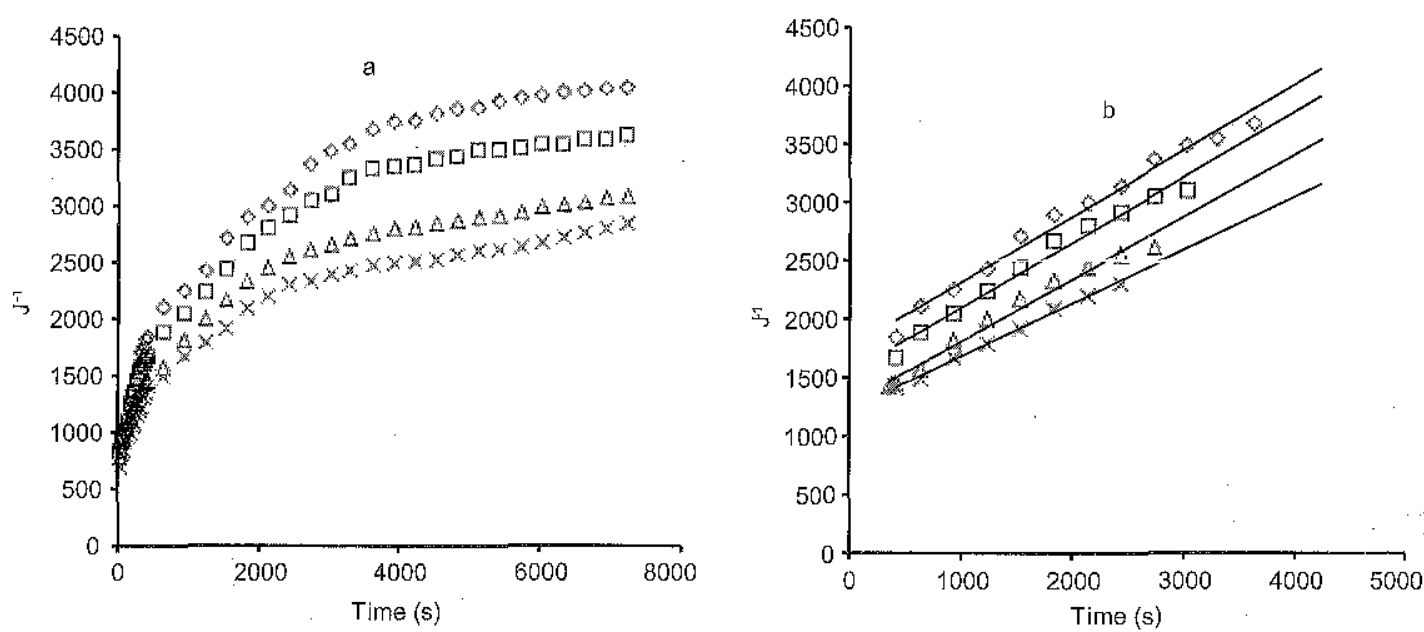

Figure 8 Effect of gas sparging on the fouling due to intermediate blocking during the microfiltration of coconut water with vatious $\varepsilon$ at $\mathrm{CFV}=1.6 \mathrm{~m} / \mathrm{s}$ and $\mathrm{TMP}=0.6 \operatorname{bar}(\vartheta, \varepsilon=0 ; \square, e=0.15 ; \varepsilon, \mathrm{e}=0.25 ; \times, \varepsilon=0.35)$.; a intermediate blocking model fitted to the flux data; b, selected linear phase of intermediate blocking model

the $R^{2}$ for linear phase evaluated by intermediate blocking of pineapple juice was not as high as those evaluated by complete blocking and cake filtration model (Table 1). The dominant fouling mechanism changes with time. It could be supposed that the fouling mechanism is relatively simple at the beginning of the process with a cleaned membrane and at the end of the process with a stable fouling layer on the membrane surface. In this study, the complete blocking mechanism appeared to be the major part of microfiltration process during the permeate flux decline period while cake filtration dominated during the steady flux period. However, the fouling mechanism of different feed solution and operating condition could influence the different of fouling mechanism.

\subsection{Effect of Gas Sparging on Fouling Resistance}

According to the above analysis, an increasing in e seems to be an effective way for enhancing the permeate flux. The effect of gas sparging on membrane resistance of pineapple juice and coconut water are shown in Table 3 and 4. It could be seen that $R_{t_{1}} R_{r f}$ and $R_{i f-e x}$ decreased with increasing of $\varepsilon$. The results indicated that the gas bubbling reduced concentration polarization and formation of fouling layer on the membrane surface leading to a decrease in fouling resistant (Table 3 and 4). Generally the reversible fouling (e.g. loss layer caused by accumulation of solutes on the membrane surface) is sensitive to the hydrodynamic conditions

Table 3 Membrane fouling during microfiltration of pineapple juice with total recycle mode at various gas injection factor at CFV0f $1.5 \mathrm{~m} / \mathrm{s}$. TMP 0.7

\begin{tabular}{lcccccc}
\hline$\varepsilon$ & $\begin{array}{c}\mathbf{R}_{\mathrm{m}}\left(\times \mathbf{1 0}^{12}\right) \\
\left(\mathbf{m}^{-1}\right)\end{array}$ & $\begin{array}{c}\mathbf{R}_{\mathrm{r}}\left(\times 10^{12}\right) \\
\left(\mathbf{m}^{-1}\right)\end{array}$ & $\begin{array}{c}\mathbf{R}_{\mathrm{rr}}\left(\times \mathbf{1 0}^{12}\right) \\
\left(\mathbf{m}^{-1}\right)\end{array}$ & $\begin{array}{c}\mathbf{R}_{\mathrm{if}}\left(\times 10^{12}\right) \\
\left(\mathbf{m}^{-1}\right)\end{array}$ & $\begin{array}{c}\mathbf{R}_{\mathrm{if}-\mathrm{cx}}\left(\times 10^{12}\right) \\
\left(\mathbf{m}^{-1}\right)\end{array}$ & $\begin{array}{c}\mathbf{R}_{\mathrm{if}-\mathrm{in}}\left(\times 10^{12}\right) \\
\left(\mathbf{m}^{-1}\right)\end{array}$ \\
\hline 0 & $0.24 \pm 0.00^{\mathrm{ns}}$ & $6.52 \pm 0.27^{\mathrm{a}}$ & $4.58 \pm 0.27^{\mathrm{a}}$ & $1.65 \pm 0.26^{\mathrm{a}}$ & $1.54 \pm 0.10^{\mathrm{a}}$ & $0.11 \pm 0.01^{\mathrm{ns}}$ \\
0.15 & $0.24 \pm 0.00^{\mathrm{ns}}$ & $5.30 \pm 0.22^{\mathrm{b}}$ & $3.54 \pm 0.22^{\mathrm{b}}$ & $1.50 \pm 0.01^{\mathrm{b}}$ & $1.39 \pm 0.01^{\mathrm{b}}$ & $0.11 \pm 0.01^{\mathrm{nb}}$ \\
0.25 & $0.24 \pm 0.00^{\mathrm{ns}}$ & $4.46 \pm 0.10^{\mathrm{c}}$ & $2.92 \pm 0.10^{\mathrm{c}}$ & $1.28 \pm 0.01^{\mathrm{c}}$ & $1.18 \pm 0.01^{\mathrm{c}}$ & $0.11 \pm 0.01^{\mathrm{ns}}$ \\
0.35 & $0.24 \pm 0.00^{\mathrm{ns}}$ & $3.95 \pm 0.10^{\mathrm{d}}$ & $2.69 \pm 0.05^{\mathrm{d}}$ & $1.02 \pm 0.10^{\mathrm{d}}$ & $0.92 \pm 0.10^{\mathrm{d}}$ & $0.10 \pm 0.00^{\mathrm{ns}}$ \\
\hline
\end{tabular}

Same letters in the same column present no statistical differences according to Duncan's multiple range test at $\mathrm{P}<0.05$ $\mathrm{N}_{\mathrm{s}}=$ no significant difference 
Table 4 Membrane fouling during microfiltration of coconut water with total recycle mode at various gas injection factor at CFVOF $1.6 \mathrm{~m} / \mathrm{s}$ TMP 0,6

\begin{tabular}{|c|c|c|c|c|c|c|}
\hline$\varepsilon$ & $\begin{array}{c}\mathrm{R}_{\mathrm{m}}\left(\times 10^{11}\right) \\
\left(\mathrm{m}^{-1}\right)\end{array}$ & $\begin{array}{r}\mathrm{R}_{\mathrm{t}}\left(\times 10^{11}\right) \\
\left(\mathrm{m}^{-1}\right)\end{array}$ & $\begin{array}{c}\mathrm{R}_{\mathrm{rr}}\left(\times 10^{11}\right) \\
\left(\mathrm{m}^{-1}\right)\end{array}$ & $\begin{array}{c}\mathrm{R}_{\mathrm{if}}\left(\times 10^{11}\right) \\
\left(\mathrm{m}^{-1}\right)\end{array}$ & $\begin{array}{c}R_{i f-e x}\left(\times 10^{11}\right) \\
\left(m^{-1}\right)\end{array}$ & $\begin{array}{c}\mathrm{R}_{\mathrm{if}-\mathrm{in}}\left(\times 10^{11}\right) \\
\left(\mathrm{m}^{-1}\right)\end{array}$ \\
\hline 0 & $4.25 \pm 0.0^{\mathrm{ns}}$ & $20.71 \pm 0.78^{\mathrm{a}}$ & $4.58 \pm 0.27^{\mathrm{a}}$ & $4.92 \pm 0.63^{\mathrm{a}}$ & $3.92 \pm 0.66^{\mathrm{a}}$ & $0.99 \pm 0.08^{\text {ns }}$ \\
\hline 0.15 & $4.25 \pm 0.0^{\mathrm{ns}}$ & $19.24 \pm 0.91^{b}$ & $3.54 \pm 0.22^{b}$ & $4.24 \pm 0.27^{\mathrm{b}}$ & $3.23 \pm 0.24^{\mathrm{b}}$ & $1.00 \pm 0.05^{\mathrm{ns}}$ \\
\hline 0.25 & $4.25 \pm 0.0^{\mathrm{ns}}$ & $16.71 \pm 0.31$ & $2.92 \pm 0.10^{\mathrm{c}}$ & $3.92 \pm 0.61^{c}$ & $2.95 \pm 0.63^{\mathrm{c}}$ & $0.97 \pm 0.04^{\mathrm{ns}}$ \\
\hline 0.35 & $4.25 \pm 0.0^{\text {ns }}$ & $14.43 \pm 0.39^{d}$ & $2.69 \pm 0.05^{d}$ & $3.69 \pm 0.39^{d}$ & $2.64 \pm 0.04^{d}$ & $1.04 \pm 0.09^{\mathrm{ns}}$ \\
\hline
\end{tabular}

Same letters in the same column present no statistical differences according to Duncan's multiple range test at $\mathrm{P}<0.05$ $\mathrm{Ns}=$ no significant difference

and could be eliminated by hydrodynamic techniques. All fouling resistance of pineapple juice was higher than the fouling of coconut water. This could be due to the higher foulants and larger particles and molecules contained in pineapple juice. However $R_{i f-i n}$ did not change when the different $\mathrm{e}$ were applied. These results indicated that the gas sparging had ro effect on internal fouling of both feed.

\subsection{CONCLUSIONS}

The dominant fouling mechanism of pineapple juice and coconut water were complete pore blocking followed by an intermediate blocking and then a cake filtration process. The complete blocking was the major reason for the Aux decline period while the calke filtration dominated during the steady flux period. Gas sparging did not affect the sequence of fouling mechanism but affected both intensive and duration of different fouling mechanism. For pineapple juices, increase in e led to a decrease in fouling intensity or kinetic constant. It was probably due to the higher of e produced the higher the vertex of the particle near the membrane surface leading to less compact of the cake. The use of $\varepsilon$ at 0.35 could remarkable reduce fouling resistant. It was important to note that gas sparging played an important role in reduction of the $R_{t,} R_{r f}$ and $R_{i f-e x}$ but the $R_{i f-i n}$. Regarding this result, the other techniques need to be developed to reduce the internal fouling.

\section{ACKNOWLEDGEMENTS}

The authors gratefully acknowledge the Faculty of Agro-Industry and Graduate School, Prince of Songkla University and the National Center for Genetic Engineering and Biotechnology (BIOTEC) of Thailand for their financial support (Project code BT-B-01-FG-18-5003).

\section{REFERENCES}

[1] Zeman, J. and Zydney, L. 1996. Microfiltration and ultrafiltration principles and applications. Marce1 Dekker. Inc. New York USA.

[2] Youravong W., Lewis, M.J. and Grandison, A.S. 2003. Critical flux in ultrafiltration of skim millk. Trans IChemE. 81(4): 303-308.

[3] Li, Z.Y., I-I-Kittikun, A. \& Youravong, W. 2008. Removal of suspended solids from tuna spleen extract by microfiltration: A batch process design and improvement. Biochem Eng. J. 38: 226-233.

[4] Ma, H. M., Hakim, L. F., Bowman, C. N. \& Davis, R. H. 2001. Factors affecting membrane reduction by surface modification and backpulsing. J. Membr. Sci. 189: 225-270.

[5] Cui, Z. F., Change, S. \& A.G. Fane, A. G. 2003 The use of gas bubbling to enhance membrane processes.J. Membr. Sci. 221: 1-35.

[6] Vela, M. C., Blanco, S. A., Garcia, J. L. \& Rodriguez, E. B. 2008. Analysis of membrane pore blocking models applied to the ultrafiltration of PEG. Sep. Purif. Technol. 62: 489-498.

[7] De Barros, S.T.D., Andrade, C.M.G., Mendes, E. S. \& Peres, L. 2003, Study of fouling 
mechanism in pineapple juice clarification by ultrafiltration. J. Membr. Sci. 215: 213-224.

[8] Cassano, A., Donate, L. \& Drioli, E. 2007. U1trafiltration of kiwifruit juice: operating parameters, juice quality and membrane fouling. J. Food Eng. 79: 613-621.

[9] Keskinler, B., Yildiz, E. Erhan, E. Dogru, M., Bayhan, Y. K. \& Akay, G. 2004. Cross flow microfiltration of low concentration-non living yeast suspensions. J. Membr. Sci. 233: 59-69.

[10] Nataraj, S. Schomacker, R. Kraume, M., Mishra, M. \& Drews, A. 2008. Analyses of polysaccharide fouling mechanisms during cross flow microfiltration.J. Membr. Sci.308: 152-161.

[11] Carneiro, L., Sa, I. D. S., Gomes, F. D. S, Matta, V.M. \& Cabral, L.M. C. 2002. Cold sterilization and clarification of pineapple juice by tangential microfiltration. Desalination. 148: 93-98.

[12] Hermia, J. 1982. Constant pressure blocking filtration laws-application to power-law nonnewtonian fluids. Trans. IChemE. 60: 183-187.
[13] Koltuniewicz, A.B., Field, R.W. \& Arnot, T.C. 1995. Cross-flow and dead-end microfiltration of oily-water emulsion: part I: experimental study and analysis of flux decline. J. Membr. Sci. 102: 93-207.

[14] Arnot, T.C., Field, R.W. \& Koltuniewicz, A.B. 2000. Cross-flow and dead-end microtiltration of oily-water emulsions: part II. mechanisms and modelling of flux decline. J. Membr. Sci. 169: 1-15.

[15] Bowen, W. R., Calvo,J.I. \& Hernandez, A. 1995. Steps of membrane blocking in flux decline during protein microfiltration.J. Membr. Sci. 101: 153-165.

[16] Hwang, K.J. \&Wu, Y.J. 2008. Flux enhancement and cake formation in air- sparged cross flow microfiltration. Chem. Eng. J. 139: 296-303.

[17] Li M., Yijiang, Z., Shouyong, Z. \& Weihong, X. 2010. Clarification of raw rice wine by ceramic microfiltration membranes and membrane fouling anaylsis. Desalination. 256: 166-173. 